\section{Antimicrobial Activity of Toothpastes Containing Natural Extracts, Chlorhexidine or Triclosan}

Andiara De Rossi, Danielly Cunha Araújo Ferreira, Raquel Assed Bezerra da Silva, Alexandra Mussolino de Queiroz, Léa Assed Bezerra da Silva, Paulo Nelson-Filho
Department of Pediatric Dentistry, School of Dentistry of Ribeirão Preto, USP - University of São Paulo, Ribeirão Preto, SP, Brazil

Correspondence: Profa. Dra. Andiara De Rossi, Avenida do Café, $\mathrm{s} / \mathrm{n}$, Monte Alegre, 14040-904 Ribeirão Preto, SP, Brasil. Tel: +55-16-36024786. e-mail: andiara@usp.br

\begin{abstract}
The objective of this in vitrostudy was to evaluate the antimicrobial effect of toothpastes containing natural extracts, chlorhexidine or triclosan. The effectiveness of toothpastes containing natural extracts (Parodontax $\left.{ }^{\circledR}\right), 0.12 \%$ chlorhexidine (Cariax $\left.{ }^{\circledR}\right), 0.3 \%$ triclosan (Sanogil $^{\oplus}$ ) or fluoride (Sorriso ${ }^{\circledast}$, control) was evaluated against yeasts, Gram-positive and Gram-negative bacteria using the disk diffusion method. Water was used as a control. Disks impregnated with the toothpastes were placed in Petri dishes containing culture media inoculated with 23 indicative microorganisms by the pour plate method. After incubation, the inhibition growth halos were measured and statistical analyses $(\alpha=0.05)$ were performed. The results indicated that all formulations, except for conventional toothpaste $\left(\right.$ Sorriso $\left.^{\circledR}\right)$, showed antimicrobial activity against Gram-positive bacteria and yeasts. The toothpaste containing natural extracts (Parodontax ${ }^{\circledast}$ ) was the only product able to inhibit the growth of Pseudomonas aeruginosa. The toothpastes containing chlorhexidine, triclosan or natural extracts presented antimicrobial activity against Gram-positive bacteria and yeasts.
\end{abstract}

Key Words: antibacterial agents, microbiology, toothpastes, natural extracts, Parodontax.

\section{Introduction}

Dental biofilm formation is a natural process that must be controlled by regular brushing to prevent the development of dental caries and periodontal disease $(1,2)$. Standard toothpaste formulas generally contain a combination of fluoride and detergents, enhancing the efficacy of biofilm control $(2,3)$. The addition of different antimicrobial agents has been suggested as a potential method for reduction, control and prevention of the accumulation of cariogenic and periodontopathogenic microorganisms $(4,5)$. However, the antimicrobial ability of such agents in combination with fluoride-containing toothpastes has not yet been effectively tested or proven (5).

Triclosan is a low-toxicity, non-ionic, chlorinated bisphenol that is compatible with toothpaste components, such as fluoride and surfactants, and it promotes inhibition of cyclooxygenase/lipoxygenase pathways and exhibits anti-inflammatory effects $(2,6)$. This agent, has been incorporated into toothpastes until the present, resulting in moderate effects on both dental biofilm formation and marginal inflammation or gingivitis (7). However, to date there are no in vitro or in vivo studies evaluating the antimicrobial effect of a $0.3 \%$ triclosan paste-based, called Sanogyl ${ }^{\oplus}$, which is available in several countries.

Currently, chlorhexidine is considered the most effective antimicrobial agent, if used as mouthwash in dentistry $(8,9)$, due to its broad-spectrum action against
Gram-positive and Gram-negative bacteria, viruses and yeasts. This effect is a result of the dicationic nature of the chlorhexidine molecule, which also affords the agent the property of a persistent antimicrobial effect on the tooth surface by both bactericidal and bacteriostatic action (8). However, attempts to formulate a toothpaste containing chlorhexidine have found difficulties, due to the inactivation of chlorhexidine by anionic ingredients $(2,6)$. Cariax ${ }^{\circledast}$ is a dentifrice that claims to contain active chlorhexidine, but no research has been conducted to investigate its antibacterial effects.

Considering that chemical agents may have side effects such as taste alteration, tongue and mucosa peeling or tooth staining when used regularly, novel phytoterapic compounds have been investigated $(10,11)$. Parodontax ${ }^{\circledR}$ is a herbalbased toothpaste containing sodium bicarbonate and several herbal components for which medicinal properties are claimed: chamomile extract has antiinflammatory properties, Echinacea extract stimulates immune response, salvia extract decreases tissue hemorrhage, myrrh extract is a natural antiseptic, and the extract of Mentha piperita is an antiseptic, anti-inflammatory and antimicrobial (11). It has been suggested that natural antimicrobials in herbal toothpastes can be as effective as chlorhexidine for immediate and delayed bacterial killing as a result of their substantivity in oral biofilms (10).

Antimicrobial properties of toothpastes have been 
studied extensively, but in vitro studies frequently evaluated single species and did not include anaerobes and other common commensal flora (5). However, the oral biofilms associated with caries and periodontal diseases are generated by multi-species interactions. Considering that antimicrobial efficacy of chemical agents may be reduced or inactivated when associated to other ingredients of toothpastes, the objective of this study was to investigate the antimicrobial efficacy of toothpastes containing triclosan $\left(\right.$ Sanogi $\left.{ }^{\otimes}\right)$, chlorhexidine $\left(\right.$ Cariax $\left.^{\circledR}\right)$ or plant extracts (Parodontax ${ }^{\oplus}$ ) against multiple species of Gram-positive bacteria, Gram-negative bacteria and yeasts. The tested hypothesis was that addition of these chemical agents into dentifrices would significantly enhance antimicrobial activity compared with conventional dentifrices containing no antimicrobial agents.

\section{Materials and Methods}

\section{Toothpastes}

The toothpastes evaluated in this study are shown in Table 1, along with their ingredients as listed on the package and the manufacturer's name. Conventional toothpaste without antimicrobial agents, Sorriso ${ }^{\oplus}$, and water were used as controls. Water was used as a control to confirm the bacterial growth.

\section{Microorganisms}

The in vitro antibacterial activity of the tested dentifrices was evaluated against 23 strains of microorganisms obtained from the American Type Culture Collection (ATCC), and field strains obtained from saliva, teeth, root canals or radiation caries. The indicator microorganisms are presented in Table 2.

\section{Antimicrobial Assay}

The antimicrobial activity of the dentifrices was determined by the disk diffusion method, using standard diffusion technique (12). All the experiments were conducted in duplicate. For the agar diffusion test (double layer agar-well technique), TSA culture medium (Tryptic-Soy-Agar; Difco, Detroit, MI, USA) was used for the streptococcus strains, and MH culture medium (Mueller Hinton Broth; Difco) was used for the remaining microorganisms. The inocula for bacterial strains were prepared in a saline suspension of the strains and adjusted to a density equivalent to the 1-4 standard of the McFarland scale, depending on the evaluated strain. In a laminar flow chamber, a base layer of $12 \mathrm{~mL} \mathrm{MH}$ or TSA at $50{ }^{\circ} \mathrm{C}$ was poured into $25 \times 150 \mathrm{~mm}$ sterile Petri dishes. After solidification of the culture medium, a seed layer composed by $8 \mathrm{~mL}$ of $\mathrm{MH}$ or TSA at $50^{\circ} \mathrm{C}$, with the addition of $10^{6}$ colony forming units (cfu) per milliliter of original inoculum, was poured onto the base layer. After solidification of the seed layer, the discs were impregnated with each toothpaste or water; the weight measured by an accurate scale for standard quantity of toothpaste and placed on the surface of each plate at equidistant points.

Two repetitions of the test were made, which means that 2 plates were used for each of the 23 test microorganisms. The plates were maintained at room temperature for $2 \mathrm{~h}$ to allow pre-diffusion of the materials. Then, the MH plates were incubated in aerobiosis, and the TSA plates were incubated in microaerophilia (candle jar system) at $37^{\circ} \mathrm{C}$ for $24 \mathrm{~h}$. After incubation, the diameters of microorganism growth inhibition zones that formed around the disks were measured in millimeters with a digital caliper (Mitutoyo, Tokyo, Japan) under reflected light.

\section{Statistical Analysis}

Data on antimicrobial activity were compared only between dentifrices evaluated by Kruskal-Wallis test and Dunn's multiple comparisons test using the Graph Pad

Table 1. Toothpastes evaluated in the study, their respective compositions and manufacturers

\begin{tabular}{|c|c|c|}
\hline Toothpaste & Composition & Manufacturer \\
\hline Cariax gingival & $\begin{array}{l}0.12 \% \text { chlorhexidine digluconate, sodium fluoride } 0.22 \mathrm{~g}(1000 \\
\text { ppm F), saccharin sodium } 0.05 \text { g. Excipient q.s.p. - } 100 \mathrm{~g} \text {. }\end{array}$ & Kin Laboratories S.A., Barcelona, Spain \\
\hline Parodontax & $\begin{array}{l}\text { Echinacea purpuraea (echinacea angustifolia) } 0.954 \mathrm{~g} \text {, mirrha } \\
\text { (commiphora myrrha) } 0.624 \mathrm{~g} \text {, Radix Ratanhiae (krameria triandra) } \\
1.248 \mathrm{~g} \text {; chamomillae (matricaria chamomilla) } 0.624 \mathrm{~g} \text {, sodium } \\
\text { hydrogen carbonate } 67.91 \mathrm{~g}, \mathrm{p} \text {-hydroxybenzoic acid benzyl ester } \\
0.05 \mathrm{~g} \text {, saccharin sodium } 0.0164 \mathrm{~g} \text {, excipient q.s.p. } 100 \mathrm{~g} \text {. }\end{array}$ & $\begin{array}{l}\text { GlaxoSmithKline Consumer Healthcare B.V., } \\
\text { Utrecht, The Netherlands }\end{array}$ \\
\hline Sanogil & $\begin{array}{l}\text { Water, silica, hydrated sorbitol, PEG-32, sodium lauryl } \\
\text { sulfate, flavor, cellulose gum, zinc citrate, } 0.3 \% \text { triclosan, } \\
\text { limonene, sodium fluoride ( } 1450 \mathrm{ppm} \mathrm{F} \text { ). }\end{array}$ & Elida Gibbs-Fabergé, Paris, France \\
\hline Sorriso & $\begin{array}{l}\text { Water, calcium carbonate, sorbitol, sodium lauryl sulfate, flavoring, sodium } \\
\text { monofluorophosphate, sodium silicate; cellulose, sodium bicarbonate, } \\
\text { sodium saccharin, formaldehyde, sodium monofluorophosphate (control) }\end{array}$ & Kolynos do Brasil Ltda, São Paulo, SP, Brazil \\
\hline
\end{tabular}


Prism 4 software (GraphPad Inc., San Diego, CA, USA). A significance level of $5 \%$ was se for all analyses.

\section{Results}

The conventional toothpaste $\left(\right.$ Sorriso $\left.^{\circ}\right)$ did not show antimicrobial activity against any of the 23 tested microorganisms, similar to the water control $(p>0.05)$ (Table 2 and Fig. 1). When compared to water and conventional toothpaste, all toothpastes containing antimicrobial agents showed antimicrobial activity $(p<0.0001)$, with no significant differences ( $p>0.05$ ) (Fig. 1). However, the dentifrice containing natural plant extracts (Parodontax ${ }^{\circ}$ ) was the only formulation that had activity against Gramnegative bacteria (Psudomonas aeruginosa) and the only product that showed no action against Enterococcus faecalis (Table 2 and Fig. 1).

\section{Discussion}

The addition of antimicrobial agents to conventional toothpastes aims to increase effectiveness in the control or elimination of microorganisms involved in a wide variety of microbial infections in the human mouth and body, such as Streptococcus mutans and Streptococcus sobrinus,

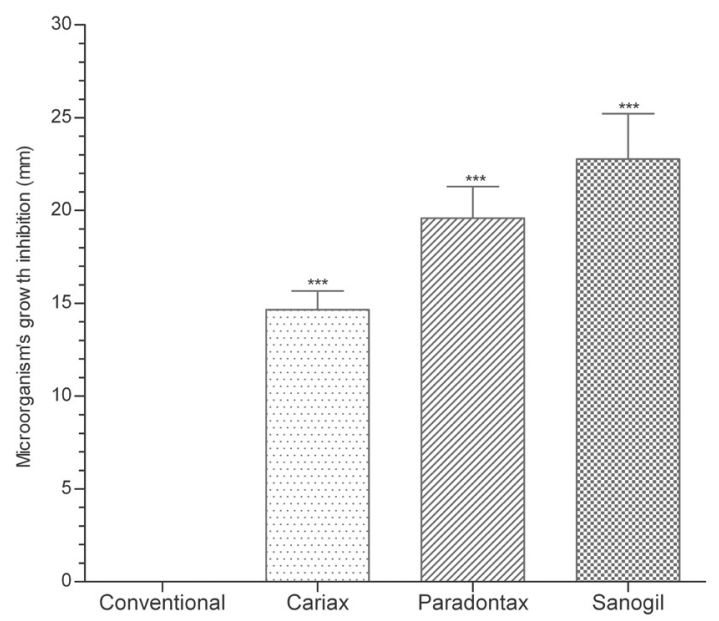

Figure 1. Means ( \pm standard error of the mean) of microorganism growth inhibition zones of each toothpaste. ${ }^{* * *} p<0.0001$.

Table 2. Tested microorganisms, origin, morphotypes and values of the mean ( $\left.\pm \mathrm{SEM}^{*}\right)$ of microorganism growth inhibition zones for each toothpaste

\begin{tabular}{|c|c|c|c|c|c|c|c|}
\hline Microorganism & Origin & Morphotypes & Water & Convent. & Cariax & Sanogil & Paradontax \\
\hline K. rhizophila & ATCC- 9341 & Gram- cocci & 0.0 & 0.0 & 18.00 & 26,00 & $22.50^{* *}$ \\
\hline S. aureus & ATCC- 25923 & Gram+ cocci & 0.0 & 0.0 & 17.00 & $32.00^{* * *}$ & 13.00 \\
\hline S. aureus & ATCC- 6538 & Gram+ cocci & 0.0 & 0.0 & 17.00 & $32.00^{* * *}$ & 15.50 \\
\hline S. aureus & CC- Penicillinase positive & Gram+ cocci & 0.0 & 0.0 & 16.50 & $58.00^{* *}$ & 18.00 \\
\hline S. aureus & CC- Penicillinase negative & Gram+ cocci & 0.0 & 0.0 & 16.50 & $36.00^{* * *}$ & 13.00 \\
\hline E. faecalis & ATCC- 10541 & Gram+ cocci & 0.0 & 0.0 & 12.50 & 14.00 & $0.00^{* *}$ \\
\hline S. mutans & CC- Saliva & Gram+ cocci & 0.0 & 0.0 & 16.50 & 24.00 & $25.00^{* *}$ \\
\hline S. mutans & CC- Saliva & Gram+ cocci & 0.0 & 0.0 & 16.50 & 23.00 & $30.00^{* * *}$ \\
\hline S. mutans & CC- Saliva & Gram+ cocci & 0.0 & 0.0 & 15.00 & $29.50^{* *}$ & $30.00^{* *}$ \\
\hline S. sobrinus & CC- Saliva & Gram+ cocci & 0.0 & 0.0 & 17.50 & 21.00 & $30.00^{* * *}$ \\
\hline S. sobrinus & CC- Saliva & Gram+ cocci & 0.0 & 0.0 & 16.00 & 21.00 & $30.00^{* *}$ \\
\hline S. mutans & CC- Root canal & Gram+ cocci & 0.0 & 0.0 & 17.00 & 24.00 & 16.00 \\
\hline S. sobrinus & CC- Saliva & Gram+ cocci & 0.0 & 0.0 & 18.50 & $26.50^{* * *}$ & $31.00^{* * *}$ \\
\hline S. sobrinus & CC- Saliva & Gram+ cocci & 0.0 & 0.0 & 17.00 & 25.00 & $29.50^{* *}$ \\
\hline S. mutans & ATCC- 25175 & Gram+ cocci & 0.0 & 0.0 & 15.00 & 25.00 & $28.00^{* *}$ \\
\hline E. coli & ATCC- 10538 & Gram- bacilli & 0.0 & 0.0 & 12.50 & 15.50 & 14.50 \\
\hline E. coli & Field strain & Gram- bacilli & 0.0 & 0.0 & 14.00 & $28.00^{* * *}$ & 15.00 \\
\hline P. aeruginosa & ATCC- 2327 & Gram- bacilli & 0.0 & 0.0 & $0.00^{* * *}$ & $0.00^{* * *}$ & 13.50 \\
\hline P. aeruginosa & Field strain & Gram- bacilli & 0.0 & 0.0 & $0.00^{* * *}$ & $0.00^{* * *}$ & 17.50 \\
\hline C. albicans & ATCC- 1023 & Yeast & 0.0 & 0.0 & 17.00 & 16.00 & 16.50 \\
\hline C. albicans & CC- Caries radiation & Yeast & 0.0 & 0.0 & 15.00 & 17.00 & 15.00 \\
\hline C. albicans & CC- Saliva & Yeast & 0.0 & 0.0 & 15.00 & 16.00 & 12.00 \\
\hline C. tropicalis & CC- Denture & Yeast & 0.0 & 0.0 & 17.00 & 14.00 & 15.00 \\
\hline Mean ( \pm S.E.M.) & & & $0( \pm 0)$ & $0( \pm 0)$ & $14.65( \pm 1.02)$ & $22.76( \pm 2.46)$ & $19.59( \pm 1.75)$ \\
\hline
\end{tabular}

*S.E.M.: Standard error of the mean. ** Statistically significant difference. 
the primary etiological agents of dental caries $(13,14)$. Furthermore, $P$. aeruginosa and $E$. faecalis (15) are related to periodontal diseases, and Candida albicans, the most common fungal pathogen, is involved in candidiasis and most superficial or systemic infections (16), even dental caries (17). However, assessment of the antimicrobial activity of commercial toothpaste is important because the preparations generally contain a complex mixture of active ingredients that may not produce the desired effect (18). Thus, the objective of this study was to evaluate commercially available toothpastes that include the most widely used and most studied antimicrobial agents in their composition $(2,3,6,9,10)$. In addition, the antimicrobial activity was evaluated in vitro for a large number of microorganisms from oral biofilm, including cariogenic and periodontopathogenic microorganisms and yeasts. It has been recently suggested that the antimicrobial activity of dentifrices should be tested by in vitro evaluations prior to randomized controlled trials (5), which are required in future studies to evaluate the possible in vivo benefits of these dentifrices.

Although the disk diffusion method is suitable for fluid materials like water, it has been also used for antimicrobial evaluation of semi-solid materials that are fluid in the presence of saliva or water, such as toothpaste $(3,4,10,12,19)$. However, these studies used a small number of microorganism strains $(3,10,19)$ and were restricted to the evaluation of standard strains (ATCC). In the present study, 23 strains of microorganisms present in the oral cavity were used, including standard strains as well as field strains isolated from saliva, dentures, root canals or radiation caries lesions. Water was used as control like in other studies $(4,19)$ to confirm the microbial growth around the disk. In this study was used a conventional toothpaste without antimicrobial agents as control (Sorriso); thus providing the same consistency of the experimental groups.

The statistical analysis of this study was performed comparing dentifrices among themselves, and no statistical analysis was performed comparing the microorganisms. This way of comparison, i.e. comparing the action of the toothpastes was made in similar studies $(4,19)$. According to the obtained results, toothpastes containing natural extracts, chlorhexidine or triclosan presented antimicrobial activity against Gram-positive bacteria and yeasts. In a similar in vitro study examining the antimicrobial activity of different toothpastes containing natural extracts, a dentifrice containing Echinacea, a substance also present in the natural dentifrice evaluated in this study (Parodontax ${ }^{\otimes}$ ), showed no antimicrobial activity against S. mutans and C. albicans (19). These results contradict this study, as the herbal-based toothpaste, Parodontax ${ }^{\circledast}$, was highly effective against $S$. mutans and C. albicans.
Despite its lack of action against $E$. faecalis, it was the only dentifrice to have an effect on Gram-negative bacteria (P. aeruginosa). This difference can be explained by the different herbal components of Parodontax ${ }^{\oplus}$, including chamomile, sage, rhatany, myrrh (which is a natural antiseptic) and peppermint oil (which demonstrates antiseptic, anti-inflammatory and antimicrobial properties). It is noteworthy that E. coli and C. albicans are also etiologically associated with carious lesions (17), while $P$. aeruginosa is associated with periodontal diseases (15). The few controlled trials evaluating this herbal toothpaste have had contradictory findings; some studies reported a significant decrease in plaque, bleeding on probing or gingivitis when compared with a control dentifrice $(20,21)$, while others found no significant clinical advantage over conventional toothpaste with fluoride $(11,22)$. Nevertheless, Parodonta $x^{\oplus}$ decreased both plaque and gingivitis (11). More clinical studies are needed to assess the effects of Parodontax $x^{\oplus}$ against cariogenic and periodontopathogenic microorganisms and yeasts, and to determine its mechanism of action and potential substantivity in oral biofilms. Parodonta $x^{\oplus}$ has shown to be absorbed in oral biofilms and present substantivity, similar to chlorhexidine $(1,10)$.

Although chlorhexidine in considered the gold standard of oral antiseptics, its antibacterial effect in dentifrices may be influenced by other ingredients in the dentifrice composition such as sodium lauryl sulfate, an anionic ingredient that may inhibit chlorhexidine action $(1,2,4)$. However, in the present study, the dentifrice with chlorhexidine $\left(\mathrm{Cariax}^{\oplus}\right)$ showed antimicrobial activity against all tested microorganisms except the Gramnegative microorganism $P$. aeruginosa, showing similarity to dentifrices containing natural extracts. The toothpaste containing triclosan (Sanogi $\left.\right|^{\odot}$ ) showed the highest antimicrobial activity $(p<0.01)$ against Gram-positive microorganisms and yeasts; however, it did not demonstrate antimicrobial activity against $P$. aeruginosa. These results are consistent with the results of the study by Prasanth (4), which showed that triclosan-based toothpastes are effective against $E$. coli, S. mutans and C. albicans. Clinical investigations suggest that the use of a dentifrice containing $0.3 \%$ triclosan may reduce halitosis (23), dental biofilm formation $(23,24)$, supragingival calculus formation and reduce clinical signs of inflammation in cases of gingivitis (24) or peri-implant mucositis at six months, when compared with the use of a standard fluoride dentifrice (25). The standard fluoride dentifrice evaluated in our study (Sorriso) did not show antimicrobial activity against any of the tested microorganisms.

It may be concluded that the addition of plant extracts, chlorhexidine or triclosan to dentifrices can result in effective antimicrobial activity against all the evaluated 
Gram-positive bacteria and yeasts, and the plant extractbased dentifrice was the only product able to inhibit the growth of Gram-negative bacteria (P. aeruginosa). However, further studies are required to evaluate their clinical advantages in the treatment or prevention of biofilm-mediated diseases. This study demonstrated the antimicrobial efficacy of toothpastes containing natural extracts, chlorhexidine or triclosan against a variety of microorganisms involved in most common oral diseases, including caries and periodontal diseases, using standard disk diffusion method. The addition of natural plant extracts to toothpastes can increase the antimicrobial spectrum, thus reducing, controlling or preventing oral diseases. Further studies are needed to evaluate their clinical advantages in the treatment or prevention of biofilm-mediated diseases.

\section{Resumo}

0 objetivo deste estudo in vitro foi avaliar o efeito antimicrobiano de dentifricios contendo extratos naturais, clorexidina ou triclosan. A efetividade dos dentifricios contendo extratos naturais (Parodontax ${ }^{\circledR}$ ), $0,12 \%$ de clorexidina (Cariax ${ }^{\circledR}$ ), 0,3\% de triclosan (Sanogil ${ }^{\circledR}$ ) ou flúor (Sorriso ${ }^{\circledR}$, controle) foi avaliada contra leveduras, bactérias Gram-positivas e Gram-negativas utilizando o método de difusão em disco. A água foi como um controle. Discos impregnados com os dentifricios foram colocados em placas de Petri contendo meio de cultura inoculados com 23 microrganismos indicadores pelo método "pour plate". Após a incubação, os halos de inibição do crescimento foram medidos e as análises estatísticas $(\alpha=0,05)$ foram realizadas. 0 s resultados indicaram que todas as formulações, com exceção do dentifrício convencional (Sorriso ${ }^{\circledR}$ ), apresentaram atividade antimicrobiana contra bactérias Gram-positivas e leveduras. 0 dentifrício contendo extratos naturais (Parodontax ${ }^{\circledR}$ ) foi o único produto capaz de inibir o crescimento de Pseudomonas aeruginosa. Os dentifricios contendo clorexidina, triclosan ou extratos naturais apresentaram atividade antimicrobiana contra bactérias Grampositivas e leveduras.

\section{Acknowledgements}

The authors are grateful to Professor Izabel Yoko Ito (In memoriam) and to the faculty members of the School of Pharmaceutical Sciences of Ribeirão Preto, University of São Paulo, for their dedication to research and for allowing us to conduct this study at their facilities.

\section{References}

1. Arweiler NB, Auschill TM, Reich E, Netuschil L. Substantivity of toothpaste slurries and their effect on reestablishment of the dental biofilm. J Clin Periodontol 2002; 29:615-621.

2. Davies RM. Toothpaste in the control of plaque/gingivitis and periodontitis. Periodontol 2000 2008;48:23-30.

3. Marsh PD. Controlling the oral biofilm with antimicrobials. J Dent 2010; 38 Suppl 1:S11-15.

4. Prasanth M. Antimicrobial efficacy of different toothpastes and mouth rinses: an in vitro study. Dent Res J [Isfahan] 2011;8:85-94.

5. Maltz $M$, Beighton D. Multidisciplinary research agenda for novel antimicrobial agents for caries prevention and treatment. Adv Dent
Res 2012;24:133-136.

6. Davies R, Scully C, Preston AJ. Dentifrices-an update. Med Oral Patol Oral Cir Bucal 2010;15:976-982.

7. Nogueira-Filho GR, Toledo S, Cury JA. Effect of 3 dentifrices containing triclosan and various additives. An experimental gingivitis study. J Clin Periodontol. 2000;27:494-498.

8. Jones CG. Chlorhexidine: is it still the gold standard? Periodontol 2000 1997;15:55-62.

9. Twetman S. Antimicrobials in future caries control? A review with special reference to chlorhexidine treatment. Caries Res 2004;38:223229.

10. Verkaik MJ, Busscher HJ, Jager D, Slomp AM, Abbas F, van der Mei HC. Efficacy of natural antimicrobials in toothpaste formulations against oral biofilms in vitro. J Dent 2011;39:218-224.

11. Pannuti CM, Mattos JP, Ranoya PN, Jesus AM, Lotufo RF, Romito GA. Clinical effect of a herbal dentifrice on the control of plaque and gingivitis: a double-blind study. Pesqui Odontol Bras 2003;17:314-318.

12. Barry $A L$, Thornsberry $C$. Susceptibility tests: diffusion test procedures. In: Balows A, ed. Manual of clinical microbiology. $5^{\text {th }}$ ed. Washington: American Society for Microbiology; 1991:1117-1125.

13. Loesche WJ. The identification of bacteria associated with periodontal disease and dental caries by enzymatic methods. Oral Microbiol Immunol 1986;1:65-72.

14. Saravia ME, Nelson-Filho $P$, Silva RA, De Rossi $A$, Faria $G$, Silva LA. Recovery of mutans streptococci on MSB, SB-20 and SB-20M agar media. Arch Oral Biol 2013;58:311-316.

15. Gonçalves LS, Souto R, Colombo AP. Detection of Helicobacter pylori, Enterococcus faecalis, and Pseudomonas aeruginosa in the subgingival biofilm of HIV-infected subjects undergoing HAART with chronic periodontitis. Eur J Clin Microbiol Infect Dis 2009;28:13351342.

16. Thein ZM, Samaranayake YH, Samaranayake LP. Effect of oral bacteria on growth and survival of Candida albicans biofilms. Arch Oral Biol 2006; 51:672-680.

17. Moalic E, Gestalin A, Quinio D, Gest PE, Zerilli A, Le Flohic AM. The extent of oral fungal flora in 353 students and possible relationships with dental caries. Caries Res 2001;35:149-155.

18. Binney A, Addy M, Owens J, Faulkner J. A comparison of triclosan and stannous fluoride toothpastes for inhibition of plaque regrowth. A crossover study designed to assess carry over. J Clin Periodontol 1997;24:166-170.

19. Lee SS, Zhang W, Li Y. The antimicrobial potential of 14 natural herbal dentifrices: results of an in vitro diffusion method study. J Am Dent Assoc 2004;135:1133-1141.

20. Yankell SL, Emling R, Perez B. Six-month evaluation of Paradontax dentifrice compared to a placebo dentifrice. J Clin Dent 1993;4:26-30.

21. Saxer UP, Menghini G, Bohnert KJ, Ley F. The effect of two toothpastes on plaque and gingival inflamation. J Clin Dent 1995;6:154-156.

22. Hu D, Zhang YP, DeVizio W, Proskin HM. A clinical investigation of the efficacy of two dentifrices for controlling oral malodor and plaque microflora overnight. J Clin Dent 2008;19:106-110.

23. Mateu FA, Boneta AE, DeVizio W, Stewart B, Proskin HM. A clinical investigation of the efficacy of two dentifrices for controlling established supragingival plaque and gingivitis. J Clin Dent 2008;19:85-94.

24. Schiff $T$, Delgado $E_{1}$ DeVizio W, Proskin HM. A clinical investigation of the efficacy of two dentifrices for the reduction of supragingival calculus formation. J Clin Dent 2008;19:102-105.

25. Ramberg $P$, Lindhe J, Botticelli D, Botticelli $A$. The effect of a triclosan dentifrice on mucositis in subjects with dental implants: a six-month clinical study. J Clin Dent 2009;20:103-107. 